\title{
Airport Ground Operations Risks and Establishment of the Safety Indicators
}

\author{
Slobodan Stojić \\ Department of Air Transport Department \\ Faculty of Transportation Sciences, Czech Technical \\ University \\ Horská 3, Praha 2, 128 03, Czech Republic \\ stojislo@fd.cvut.cz
}

\author{
Matouš Janáček \\ Department of Air Transport Department \\ Faculty of Transportation Sciences, Czech Technical \\ University \\ Horská 3, Praha 2, 128 03, Czech Republic \\ janacmat@fd.cvut.cz
}

\begin{abstract}
This paper brings a relatively new approach to air transport safety. This approach introduces the safety indicators whose application's primary goal is to reduce the number of aviation safety events and to search for their causes. These causes are defined as factors contributing to safety event realisation. These are supposed to be adequately identified and analysed in order to be prevented or at least mitigated in future. Defined safety indicators are focused on airport processes and subjects.
\end{abstract}

Keywords - Safety indicators, contributing factors, risk, airport ground operations

\section{INTRODUCTION}

Safety will always be an integral part of aviation. It is supposed to be comprehended in relation to existence of some hazard or safety risk [1]. In order to better control safety as such, there is a constant need for dynamic development of safety systems in a way ensuring future accident avoidance and potential risk mitigation. Due to a character of safety issues, development of such systems will never be finalised, in other words, it will always require an improvement.

Statistically, the most aviation incidents happened at the airports, primarily on aprons, taxiways and runways [2] [3]. Subjects or objects involved in some incidents are not always and exclusively airplanes, but airport handling equipment and vehicles used for various airport operations. To avoid such incidents, it is necessary for an organisation, in this case an airport to set safety system properly. Setting must fit current safety related issues and meet the airport management requirements.

In order to obtain required operation certificates, airports must have approved airport operation manual, which includes establishment of safety management system, ensuring the systematic approach to management of safety. Such system is focused on a collection of safety data, which are further analysed in order to locate potential safety issues that could lead to unwanted events.

The approach to identification and description of hazards and risks related to airport ground operations presented in this article, involves active search for contributing factors of aviation safety events and introduces a tool known as safety indicators. Safety indicators are understood as measurable variables creating a picture of current state in the area of safety within respective organisation. Safety indicators establishment is supported by ICAO, and it follows a higher goal of safety performance measurement [4]. To support definition and effective application of such indicators a high-quality safety data are needed. Therefore, introduction of safety indicators should be always followed by more efficient data collection. Definition of safety indicators supports the process of identification of contributory factors. Practically, focusing on these factors during definition of indicators should ensure a more proactive approach to prevention of safety events. The main idea is to prevent these factors to become an actual cause of some accident, timely and in a most effective way.

\section{STATISTICS OF AIR TRANSPORT ACCIDENTS}

According to current accident rates, it could be concluded that air transport safety continuously increases since 1960 when air transport started to be widely used. The following section presents historical data of air transport accidents together with the numbers of flights per year.

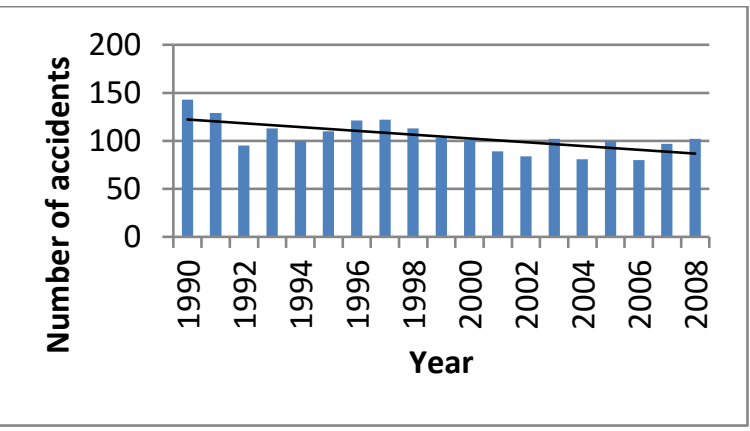

Graph 1 - Number of accidents per year (1990-2008), Commercial air transport - aircraft with maximum takeoff weight more than $5700 \mathrm{~kg}$ Source: ICAO ADREP 
The first graph (Graph 1) shows the evolution of aviation accidents from 1990 to 2008 . These are data for a commercial air transport, for aircraft with a maximum take-off weight more than $5700 \mathrm{~kg}$. It includes all accidents that took place during processes on the ground, or accident during a flight. The graph (Graph 1) shows a slightly downward trend. Although it might seem that safety has not increased significantly, statistics do not include the growing number of flights per year.

Second graph (Graph 2) takes into account increased number of flights per year. This graph does not represent the number of accidents but accident rates, which are calculated as the number of accidents in the year divided by the number of flights. It demonstrates that development of the air transport safety by means of various systems, which include the safety management system, actually works.

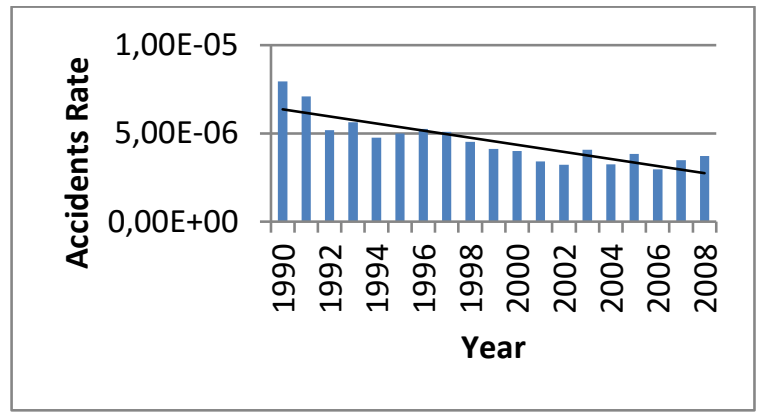

Graph 2 - Accidents rate per year (1990-2008), Commercial air transport - aircraft with maximum takeoff weight more than $5700 \mathrm{~kg}$ Source: ICAO ADREP

As previously said, the focus of article is safety of the airport ground operations. Therefore, it is important to show the statistics of accidents during different airport operations and flight phases. The following graph (Graph 3) includes distributions of accidents according to phases of flight and ground movements during which they materialised.

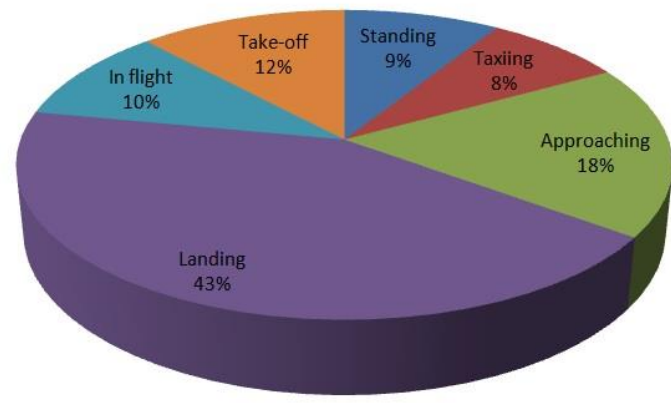

Graph 3 - Distribution of the accidents according to the flight phase in 2013, Source: ICAO Safety Report 2014

\section{DEFINING THE HAZARDS AND RISKS AT THE AIRPORT}

In order to present individual safety related issues it is important that all used terms are understood correctly, especially terms hazard and risk.

Hazard relates to any object, event, situation, etc. that could be a precondition for some event or could support negative impacts on the respective system. Risk on the other hand is understood as probability of event realisation that influences a system in a negative manner. Within this article risks will not be interpreted through methodically defined values, but through a description of the events to which they relate to.

Some events could be cause of other events, or hazards could lead to other hazards, so for purpose of their understandable interpretation each particular safety issue should be approached individually. This means that in some case one safety event will be understood as hazard to which are defined risks of some events realisation, but in other case the same event will represent final event to which are contributing factors linked.

Hazards and risks can be identified and evaluated through various sources of collected data like events reporting, audits, etc. Definition of hazards and risks related to ground operations at the airport is almost always followed by search for the possible consequences and, if possible, a risk reduction to an acceptable level. Similarly as in other industry branches, a problem regarding existence of hazards and risks is placed high on the airport management's list of priorities, due to a fact that such problems could lead to an accident, resulting in injuries, loss of lives and damages. Therefore, it is necessary to recognize and properly define the hazards and risks on time and to focus activities on their mitigation as much as possible.

A good example of hazard at the airport is a problem related to a failure of a radio communication, which is essential for air traffic control during operations at the airport and during flights. Communication is highly important for various operations, so it is supported by other redundant systems. Voice communication is enabled through three basic and mutually independent systems: main, back-up and emergency system. It is rare that all three systems fail simultaneously, however it happens, but much more frequently there are just some interferences. Such issues are also understood as a failure of a radio communication. These issues could have causes such as bad weather, various sources of interruptions, external interference, jamming of the devices in the aircraft, failure of the receiver or transmitter, etc. If such situation happens, the following consequences could be significant. As previously mentioned, risks related to such hazard will be interpreted only through stating the safety events that could occur. Failure of communication therefore could trigger runway or taxiway incursion, collision with another aircraft or with the airport infrastructure and equipment, etc.

Another example of significant hazard could be a lack of coordination between employees during particular activities. It includes the absence or lack of cooperation between personnel in the situations where that is required by legislation. A practical example of such issue is an absence of visual guidance during 
vehicle manoeuvring around the aircraft. Such event could be caused by various contributing factors. The most common ones are insufficient number of handling personnel, insufficient training of employees, emergency or unusual situations, etc. Existence of these issues leads to increased risk of realisation of safety events, for instance a collision of vehicles and aircraft, or other equipment and pieces of infrastructure.

For correct understanding of hazards and potential risks, these should be interpreted clearly and systematically. The following table (Table 1) introduces a detailed description of an identified hazard, in this case a low visibility conditions. Table defines hazard as such, its causes, safety events that could be triggered and regulations dealing with this kind of issues.

Table 1 - Example of the risk at the airport

\begin{tabular}{|l|l|}
\hline Hazard & $\begin{array}{l}\text { Operations during low visibility } \\
\text { conditions }\end{array}$ \\
\hline Definition & $\begin{array}{l}\text { Special operating procedures performed } \\
\text { when visibility falls below a certain } \\
\text { minimum. Operation under low visibility } \\
\text { begins when the runway visibility range is } \\
600 \text { m or less and clouds base is 200 feet } \\
\text { or less. Operations under low visibility are } \\
\text { terminated when runway visibility range } \\
\text { is greater than 600 m and when clouds } \\
\text { base is more than 200 ft. }\end{array}$ \\
\hline $\begin{array}{l}\text { Cause } \\
\text { events that } \\
\text { could be } \\
\text { triggered }\end{array}$ & $\begin{array}{l}\text { Bad weather, a fire near the airport, fog, } \\
\text { smog situation }\end{array}$ \\
\hline Regulation & $\begin{array}{l}\text { Runay and Taxiway incursion, an } \\
\text { an animal, FOD ingestion }\end{array}$ \\
\hline $\begin{array}{l}\text { AIP AD 1. collision with } \\
\text { https://lis.rlp.cz/ais_data/aip/data/valid/a } \\
\text { 1-1.pdf }\end{array}$
\end{tabular}

\section{DEFINITION OF CONTRIBUTING FACTORS}

Factors contributing to an accident or incident are defined as actions, omissions, events, conditions, or their combination, whose removal, avoidance or absence would reduce the likelihood of an accident or mitigate the seriousness of the accident or incident consequences. Discovering the contributing factors of some safety related event does not determine fault or criminal liability for performed activities [5].

In order to determine why an accident or incident occurs, it is important to define factors leading to events and factors that occurred during an event. The meaning of the contributing factors is to adequately describe the event and to explain why it actually happened. Each event could be described by relevant event type, descriptive or explanatory factors. These are defined by ICAO as parts of ADREP taxonomy used by ADREP system for safety event reporting [6]. The European reporting system ECCAIRS uses taxonomy which is based on ADREP. The terms defined within part of the ADREP taxonomy named "Events" represent possible events that have impact on safety. These are used for unified classification and following description of a reported event.

Descriptive factors are used to describe events in more details, or more precisely, to define relevant objects or processes involved in the event by assigning predefined terms, written under a certain code for a simplified utilization by automated systems. This coding system is used for all taxonomy parts. Explanatory factors on the other side define a role of human factor.

It should be noted that contributing factors are not static but suitable for flexible and individual use. Assigning particular contributory factors to some events requires a relevant knowledge and correct understanding of all aspects. Therefore, contributing factors are defined during investigation phase, where qualified person, in most cases safety inspector or manager defines individual factors according to available data collected through reporting system. For more convenient event description there are some general principles on how to approach it. An event is described as precisely as possible, then the individual factors are assigned to it in order to systematically describe what happened or what did not work. Event must be described in a chronological order to preserve eventual chain of mutually related events. This should provide a whole picture of the common events, leaving a possibility to trace a similar future events.

ADREP taxonomy with all its parts has complex structure. Therefore, there are some efforts spent on taxonomy creators' level, leading to integration of the individual taxonomy parts into one consistent taxonomy of event types. This does not influences proposed approach, in contrary, it makes it more clear and convenient.

The following table (Table 2) represents an example of contributing factors, together with their description.

Table 2 - Example of contributing factors

\begin{tabular}{|l|l|}
\hline \multicolumn{1}{|c|}{ Contributing factor } & \multicolumn{1}{c|}{ Description } \\
\hline $\begin{array}{l}\text { Procedure not } \\
\text { performed or incorrect }\end{array}$ & $\begin{array}{l}\text { Movement of vehicles on } \\
\text { a taxiway }\end{array}$ \\
\hline Understaffing & $\begin{array}{l}\text { Absence of vehicle } \\
\text { guidance }\end{array}$ \\
\hline Workload & $\begin{array}{l}\text { One person performs } \\
\text { more operations alone }\end{array}$ \\
\hline $\begin{array}{l}\text { Incorrect use of } \\
\text { equipment }\end{array}$ & Non-braked vehicle \\
\hline
\end{tabular}

According to the available data, contributing factors stated in the table (Table 2) represent the most common ones. Events that occurred during ground handling at the Prague airport has for the most common cause a procedure violation. These are followed by insufficient number of engaged personnel, increased workload and incorrect use of equipment.

By stating these contributing factors, an organization, respectively a safety management, could get a clearer picture on which spots require more attention or corrective measures. Stating individual contributing factors is not enough. These 
must be continuously monitored in order to follow a trend of their occurrence. Safety indicators are within proposed approach understood as powerful instrument enabling continuous monitoring and proper reaction planning.

\section{SAFETY INDICATORS}

Indicators are measurable process variables, utilized to ensure a better view on the safety issues and to enable deeper understanding of them. Their application should support, lead or correct management decision-making process, and ensure enough data for assessment of a current safety level. Indicators should contain numeric values, must be detailed enough and updated on a regular basis [7].

If there is a functional safety management system, application of safety indicators is more convenient. To be able to use these indicators, an adequate data collection process should be established. The available data are analysed and evaluated. Gathered and analysed data create a basis for establishment of safety indicators.

Safety indicators are considered to be integral system elements. These elements define new possible safety issues, based on collected data from operational processes, which are part of everyday routine. The result of such approach is a safety model of an organization, which ensures a feedback necessary to improve a safety in particular segments. Indicators represent an effective tool for description of phenomena or events that may occur within given organization.

As already mentioned, a main condition for successful establishment of safety indicators is existence of high-quality data. These data that must be collected or measured in an appropriate manner. Good sources for data collection are event reports or safety audits, which are designed to evaluate the functional aspects of the safety system and its implementation. For safety audits it is also useful to compare the results with other similar organizations. It is recommended to perform these audits before implementing changes, and then after implementation to assess effectiveness of it [7].

Another effective data collection method is safety observation where data are gathered from event reports, or directly from observations of performed operations on the ground. Other methods are questionnaires and surveys, where appropriately created questions guide employees to describe and point out safety gaps in the system. The last applied method are interviews in which employees are asked about operational processes, aiming to coordinate, or at least to get closer to balance between the process objectives and safety measures.

\section{EXAMPLES OF SAFETY INDICATORS}

The following chapter brings a sample of defined indicators. The criteria for indicator establishment was frequency and severity of some event or contributory factor. The indicators are established for the Prague airport environment, meaning that they take into account specific needs, conditions and circumstances. There are currently few initiatives which are introducing the safety indicators solutions, giving defined sets of indicators specialised for airport requirements [8].

Research results includes two types of indicators, reactive and proactive ones. Safety management system of an airport should focus on both types of indicators [9]. Reactive indicators provide simple numbers of specific accidents realisations, meanwhile proactive ones focus more on the contributing factors. The goal of proactive indicators is to recognise or at least indicate the tendency of some processes to become a contributory factor for potential safety events.

Results of the research introduce a list of seventeen indicators, however, their eventual modification or establishment of new ones should be a flexible process, ensuring that indicators provide relevant and useful data.

The tables (Table 3, 4 and 5) define a sample of respective safety indicators. Each indicators is defined by clear and understandable title. Individual indicators are described in more detail, together with a location to which they are related to. Indicators are defined by type, determining whether indicator is understood as reactive or proactive.

Table 3 - Example of safety indicator

\begin{tabular}{|c|c|}
\hline Indicator & $\begin{array}{c}\text { The number of vehicle or } \\
\text { equipment maintenance checks }\end{array}$ \\
\hline Description & $\begin{array}{c}\text { Indicator brings a number of } \\
\text { performed maintenances. How } \\
\text { many times were vehicles checked }\end{array}$ \\
\hline Location & - \\
\hline Type & Proactive \\
\hline
\end{tabular}

Table 4 - Example of safety indicator

\begin{tabular}{|c|c|}
\hline Indicator & The number of speeding violations \\
\hline Title & $\begin{array}{c}\text { Indicator counts how many times did } \\
\text { speeding violations occur }\end{array}$ \\
\hline Location & Aprons, Airport roads \\
\hline Type & Proactive \\
\hline
\end{tabular}

Table 5 - Example of safety indicator

\begin{tabular}{|c|c|}
\hline Indicator & \\
\hline Title & $\begin{array}{l}\text { The number of found FODs on } \\
\text { apron, taxiway or runway }\end{array}$ \\
\hline Description & $\begin{array}{l}\text { Indicator counts how many times } \\
\text { was FOD found on the apron, } \\
\text { taxiway or runway }\end{array}$ \\
\hline \multirow{2}{*}{$\frac{\text { Location }}{\text { Type }}$} & Apron, Taxiway, Runway \\
\hline & Reactive \\
\hline
\end{tabular}


The first two tables represent examples of proactive indicators. Indicator titled "The number of vehicle or equipment maintenance checks" should indicate insufficiencies or incorrectness in airport equipment maintenance. It is common situation where defective baggage carts play a main role in safety event, for example inducing ground collision with the aircraft due to unserviceable brakes.

The number of found FODs on apron, taxiway or runway is an example of reactive indicator. Existence of FOD itself represents a particular safety event. Importance of FOD events monitoring lies in potential of such event to induce another probably more critical safety event.

Besides location and type of indicators, other attributes could be defined as well, according to the current needs and relevancy. The goal is to filter available data to the most useful and valuable ones in order to provide compact output for final user of indicators, in this case safety management team.

\section{CONCLUSION}

The primary focus of the article is to define hazards and events whose realisation represents a risk for an organization, in this case an airport. It also introduces examples on how the relevant and effective safety indicators for airports should be created. It describes approach to hazard and risk identification. The final results are designed safety indicators, based on relevant safety data and established with the intention to create effective mechanism leading to the eventual increase of the safety level at the airport. Conclusions based on current research confirm that such approach could help airports to effectively search for key safety issues and to better focus activities leading to their reduction.

\section{REFERENCES}

[1] ANTONSEN, STIAN. Safety culture: theory, method and improvement. Burlington, VT: Ashgate Pub. Company,c2009., ISBN 0754693945.

[2] Safety Report 2015, International Civil Aviation Organization,[Online], Available from:

http://www.icao.int/safety/Documents/ICAO_Safety_Report_2015_Web .pdf

[3] ZOGRAFOS, KONSTANTINOS. ANDREATTA, GIOVANNI ODONI, AMEDEO. Aerospace Series: Modelling and Managing Airport Performance, Červen 2013, Wiley, ISBN: 9781118535479

[4] ICAO Doc. 9859, Safety Management Manual, Third edition, 2013 Available from:

http://www.icao.int/safety/SafetyManagement/Documents/Doc.9859.3rd $\% 20$ Edition.alltext.en.pdf

[5] Letecký předpis o odborném zjišt’ování příčin leteckých nehod a incidentů, L13, Ministerstvo dopravy České republiky, Úřad pro civilní letectví, Available from:

http://lis.rlp.cz/predpisy/predpisy/dokumenty/L/L13/data/effective/hl1.pdf

[6] ICAO, ADREP Taxonomy.

Available from:

http://www.icao.int/safety/airnavigation/aig/pages/adrep-

taxonomies.aspx

[7] VITTEK, PETER. PLOS, VLADIMÍR. NĚMEC, VLADIMÍR. Bezpečnostní Indikátory - Vývoj a využití v letecké dopravě, 2012, [Online], Available from:

http://pernerscontacts.upce.cz/27_2012/Vittek.pdf

[8] ACI Recommended Practice, Airport Safety Performance Measurement - The Use of Safety Key Performance Indicators, Airports Council International, March, 2014

[9] WYMAN, OLIVER Guide to Airport Performance Measures. Airports Council International. 2012. Available from: http://www.aci.aero/Media/aci/downloads/ACI_APM_Guidebook_2_20 12.pdf 